
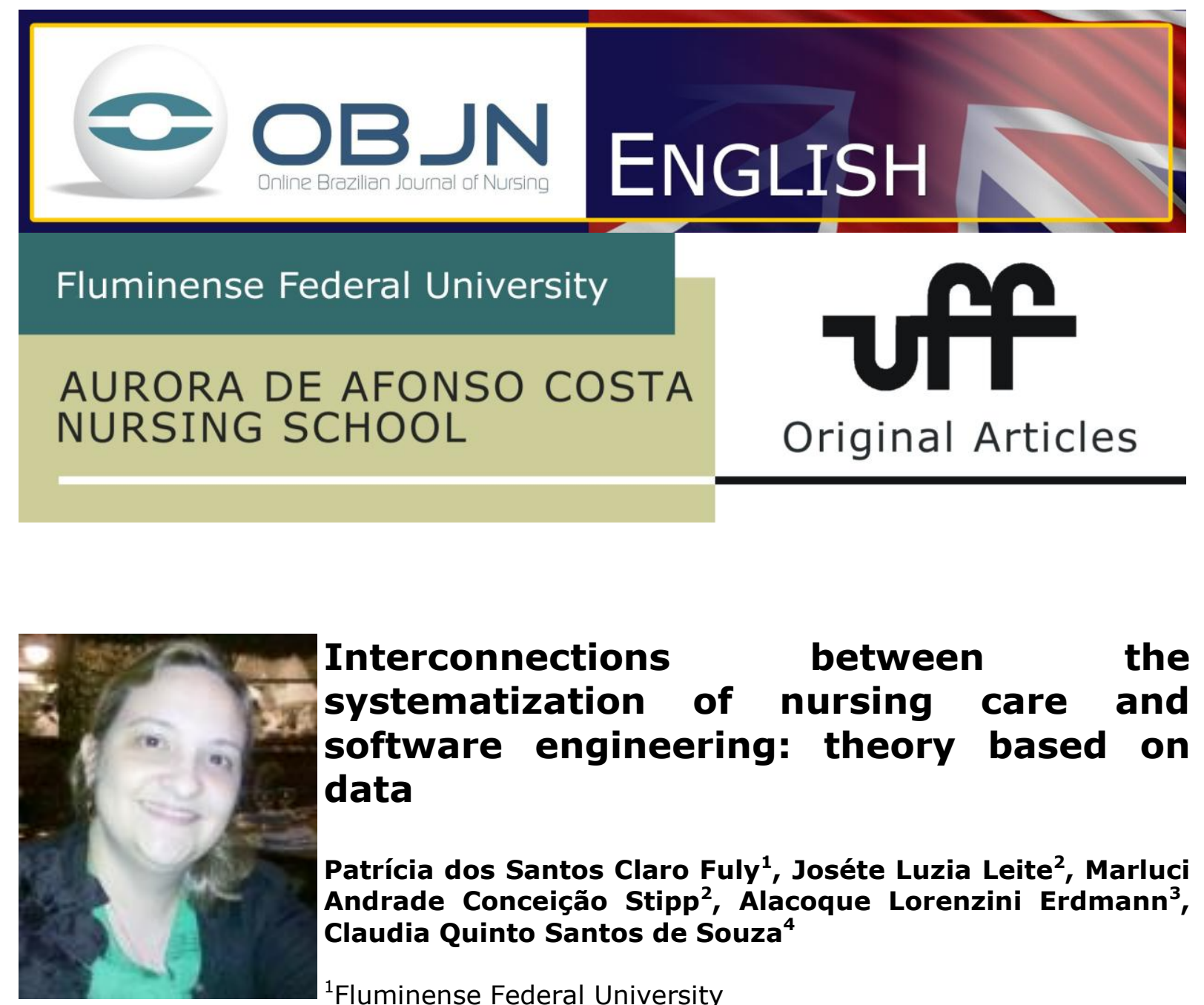

\title{
Interconnections between the systematization of nursing care and software engineering: theory based on data
}

Patrícia dos Santos Claro Fuly ${ }^{1}$, Joséte Luzia Leite ${ }^{2}$, Marluci Andrade Conceição Stipp ${ }^{2}$, Alacoque Lorenzini Erdmann ${ }^{3}$, Claudia Quinto Santos de Souza ${ }^{4}$

${ }^{1}$ Fluminense Federal University

${ }^{2}$ Rio de Janeiro Federal University

${ }^{3}$ Santa Catarina Federal University

${ }^{4}$ Brazilian National Cancer Institute

\begin{abstract}
Aims: To analyze the implementation of the Systematization of Nursing Care and discuss the interconnections between the process of implementation in a specialized hospital and software engineering.

Method: This is a qualitative study that used Grounded Theory as its methodological reference. The scenario studied was the Brazilian National Cancer Institute - Unit II, where the semi-structured interviews with nine nurses took place.

Results: This study generated five categories, among which we highlight the phenomenon Building the Basis of a System of Nursing Care.

Discussion: The understanding of a System of Nursing Care as a whole, integrated and interactive, converges to a concept of systematization.

Conclusion: When developing the paradigmatic model, the causal convenience evidenced in the category Building the Basis of a System of Nursing Care and its respective subcategories point to an empiric evolution in the implementation of this system, which has some similarities to the steps taken in software engineering.

Keywords: Nursing; Nursing Processes; Medical IT
\end{abstract}




\section{INTRODUCTION}

The nursing job is organized and systematized by a group of professionals, in which different actions, concatenated and interdependent, are part of an interactive process between the nurse and the patient and his relatives, as well as nurses and different members of the health team, to be implemented in service. These nursing actions are an integrated system of necessary care used to regenerate the patient.

Within nursing, which is a science that aims to answer human necessities, it is fundamental to understand that professional performance lacks "human-social content." Interaction, welcoming, support, comprehension, along with other factors, are the determinants for achieving better results in assistance and improvement in the quality of healthcare ${ }^{(1)}$. The meaning of "care" is broadening everyday toward a humanist and interactive perspective in order to overcome the mechanistic and reductionist care procedures. It is also considered that the nursing interventions and the results expected must be based not only on the dichotomy of health and treatment, but also on the repercussions of the disease to the patient and, consequently, the comprehensive care procedures.

From the opposition between the humanist care and the ordinary idea of the terminology system, some nurses have developed the idea of using the Systematization of Nursing Care (SNC), believing that this systematic work would lead them to a medical-curativistic model. In reality, this model focuses on the needs of the patients.

However, as SNC is a system of integral and interdependent parts that, when assembled, generate a set with an established objective and function ${ }^{(2)}$, it is, therefore, a paradox to disarticulate the idea of a global view over the human being and the systematization of care. Similar to software engineering, in this systematization no part can be disregarded as each work interdependently. To deny a partition of a system generates, as a consequence, an inconsistency in the dynamics or in the movement as a whole, thus compromising the expected results. Simultaneously, it is not possible to reduce the idea 
of a system to a systematization, the latter being an organizational process that enables the implementation of the nursing process.

Another assumption usually linked to the SNC is the development of software. This process must be interactive-incorporating, filtering, and organizing the collected information. This collection of information is usually considered the structure for the necessary tasks required to go on to build the $\mathrm{SNC}^{(3)}$.

Therefore, when thinking about the development of the SNC as an organizational process that can offer subsidies to develop interdisciplinary and humanized methods and methodologies of care, the question about the reason for a certain practice arises: the fact that the SNC centers on the illness and not the human being ${ }^{(4)}$. In reality, the situations were the focus is on the illness interferes in the implementation of SNC. The necessity of such implementation is not only based on the Brazilian Federal Nursing Council Resolution 358/2009 ${ }^{(5)}$, but also in the necessity for creating structures for the nursing job that focus on quality. It is based on this demand that this study presents as an object the experiences of nurses regarding the SNC management of quality control in professional care.

The complete study, which generated a doctoral thesis, developed a validated theory on the following central phenomenon: "Resignifying the quality management and the valorization of professional care: the implantation and implementation of systematization of nursing care." This article is part of the aforementioned thesis, and aimed to analyze the meaning of implementation of the SNC for the quality in professional care, discussing the interconnections between the process of SNC implementation in a specialized hospital in the municipality of Rio de Janeiro, and software engineering.

In this article, the focus is on the category "Building the Basis of a Nursing Assisting System" and its subcategories, which were the causal conditions of the studied phenomenon: "Resignifying the quality management and the valorization of professional care through the implantation and implementation of SNC."

\section{METHOD}

Fuly PSC, Leite JL, Stipp MAC, Erdmann AL, Souza CQS. Interconnections between the systematization of nursing care and software engineering: theory based on data. Online braz j nurs [Internet]. 2013 Apr [cited year mouth day]; 12 (1): 51 49-61. Available from: http://www.objnursing.uff.br/index.php/nursing/article/view/4099 
This is a qualitative study, with an exploratory approach. The study used as a theoretical reference the symbolic interactionism of Herbert Blumer, in association with terminologies from software engineering. The interactionism appears as a possibility for analysis of the data from the study, as it is a comprehensive approach that considers as fundamental the interactive process among the subjects in their natural environment. It enables a vast comprehension of the phenomenon, revealing and pointing to the results from the interaction between the nurse and the involved elements in the assisting process, within a specific context. It aims to observe how the interpretative process is used over those elements, considering that the meaning of the objects are emerging social products of an interactive practice in constant transformation ${ }^{(6)}$. Based on these theories, this study noticed a connection between the findings regarding the SNC implementation and the concepts related to systems and their construction.

The methodological reference used was the Grounded Theory, based on the writings of Strauss and Corbin ${ }^{(7)}$. It is an investigative qualitative methodology that, aiming to expand the scientific knowledge, extracts the meaningful aspects of lived experiences by the subjects studied, which makes it possible to interconnect theoretical constructions and the formulation of new theories ${ }^{(8)}$.

The environment of this research was the Brazilian National Cancer Institute - Unit II (INCA II, in Portuguese), a referral hospital in cancer treatment in Brazil, located in the municipality of Rio de Janeiro, a pioneer in the initiative to implant and implement SNC and aiming to acquire Hospital Accreditation.

The subjects involved in this study were nine nurses that fitted into the criteria of inclusion, and participated in the process of SNC implantation and implementation in the studied unit. They are, therefore, the only sample group. The exclusion criteria included resident nurses that were performing in the SNC implantation and implementation scenario, in the moment of implantation and implementation of SNC. All subjects showed interest in participating in this study, and formalized their participation by signing the Free and Clear Consent Agreement, according to the ethics criteria listed in the Brazilian 
National Health Council Resolution 196/96, from the Brazilian Ministry of Health ${ }^{(9)}$, which establishes the rules over studies involving human beings. This study, registered in CONEP, was approved by the Ethics in Research Committee of the Brazilian National Cancer Institute under protocol \#069/2008.

The information was collected through semi-structured interviews based on the guiding question: What is the meaning of implantation and implementation of SNC that is aimed at managing the quality of professional care? The dialogues were recorded, transcribed, and analyzed, then later sent to the three types of coding: open, axial, and selective, according to Strauss and Corbin ${ }^{(7)}$.

The categories, subcategories, and the components extracted from the referred process of coding were analyzed in order to identify the central phenomenon of this study. For such a task, the information was united and organized, aiming to integrate the structure and the process of the interviews, according to the paradigmatic model ${ }^{(7)}$.

After the process of data coding, the findings were validated by six nurses who had previous knowledge of SNC and had worked in Accredited or In Process of Accreditation Hospitals, based on the context of the study.

\section{RESULTS}

Based on the process of coding, five categories emerged. From those five categories, this study highlighted one to be studied as a phenomenon: "Building Bases of a System of Nursing Care." This category is grounded in four subcategories: 1) Building a study group (GISAE); 2) Elaborating a situational diagnosis; 3) Working in SNC pre-requisites with the nurses and; 4) Redirecting professional care. These subcategories point to evidence of an approximation between SNC and software engineering.

\section{Building a study group - GISAE}

The Group of Interest in SNC (GISAE, in Portuguese) was created to discuss the technical and scientific aspects regarding the construction and organization of SNC inside INCA II, 
with the final objective of achieving Hospital Accreditation. GISAE was the initial and fundamental step for INCA nurses to think about SNC. In these meetings, the interactive process of the nurse working with SNC pushed some of them to reflect upon this systematization, and to consider the different experiences and beliefs they had previously held regarding SNC. Such area of discussion transcended what was initially a work meeting, and the meeting developed into a space of awareness, awakening, and facilitated the exchange of experiences.

GISAE was the first group, a group to elaborate even the desire in the people to work the systematization [...]. It did exactly this interest in systematization [...]. But the interesting part it also builds up the desire in people to learn more. We started to build this interest when looking to find our own diagnoses. (POPPY)

\section{Elaborating a situational diagnosis}

This subcategory points to the evidenced necessity for diagnosing the status of the unit about the SNC, considering the importance of the results to be achieved. This recognition of the institutional reality is the fundamental step for implementing SNC and building the forms to facilitate the register of nursing care.

We created some questionnaires, and also some evaluation instruments. The questionnaires were to collect information regarding we knew each other inside the hospital. I mean we, the whole hospital. So, with that we would be based if it was a new group or not. To quantify how many nurses knew SNC. It was surveyed if a person knew what was SNC, the nursing diagnoses, if the person knows what is evolution, prescription, what is the process [...]. This was done to know where we had to start to work, from where we would star, orientate, so then we could work. (GILLYFLOWER)

\section{Working with the SNC pre-requisites with the nurses}

In this subcategory, it was observed that the situational diagnosis process motivated the search to understand the questions that involved SNC. Courses and events that related to the topic were offered to the nurses. Initially, the interesting content was related to the implantation of SNC at INCA. Later, there was a necessity for and interest in amplifying the repertory of a general SNC implementation. 
This group felt the necessity to research deeper what was systematization, the concept itself. Later, the group felt the necessity to search for the diagnosing question and, at this moment, we found a professionalization course, which we had the participation of a nurse, an auditor professor, who came to run the course [...]. Well, and together with the course we also got some nurse groups to participate in semiology courses, applied to nursing. (ORCHID)

\section{Redirecting the professional care}

This subcategory deals with the necessity of an expressive change in work processes, aiming to implant and implement SNC. To fully organize and articulate the nursing work, nurses created forms to register the treatment activities in the patient records. The lack of structure in the registries could impact the quality of the healthcare service provided, as the work developed by the nursing team demands continuity, which depends on the amount of information gathered from the patients by all members of the healthcare team.

A Study Group in Critic Thinking (GERC, in Portuguese) was created, in weekly meetings, to discuss hypothetical or real clinical cases in oncology and gynecology (INCA II specialties), in order to generate real and potential nursing diagnoses.

Besides the conceptual discussion of diagnoses, of terminologies, we created a group of clinical thinking exercises. Even before the implantation, we had this group of clinical thinking because we felt the necessity to train a specific clinic thinking in the area of nursing. (ORCHID)

\section{DISCUSSION}

The category "Building Bases of a System of Nursing Assistance" points to intrinsic processes in the modeling of systems ${ }^{(10)}$ : the comprehension of an integrated and interactive system of nursing assistance as a whole that converges to a broader concept of system, which is based on a concept that systems are sets of things or parts connected interdependently among those parts because of their meanings and existences (11).

However, it cannot be denied that the common sense has traditional ideas about the formation of a system, ideas that were born around 40 years ago, from a mechanistic, 
reductionist view, based on classical physics, that dealt with a series of linear causes; in other words, these ideas were based on phenomena that normally involved two variables, both explained by the idea of cause and effect. However, this thinking became too limited as, similar to the fields of biology, the social sciences, and behavior studies, the problems presented multiple variables. Therefore, the creation of new amplified and interdisciplinary conceptual models became necessary ${ }^{(12)}$.

The Cartesian view also found room in the area of healthcare, leading to the fragmentation of the whole for a better comprehension of the parts. Despite this fact, this fragmentation has been considered insufficient for patient care regarding the idea of multi-casualty of a phenomenon. The idea of new, interdisciplinary conceptual models, after some time, found more space when it was able to work with the different needs of the human being, thus widening the perspectives in health sciences. Thus, the new paradigmatic view, which considers the whole through the interaction and integration of the parts, was and continues to be, essential to the development of nursing and to the sciences as a whole.

When analyzing SNC based on the General Theory of Systems, we can observe some intersections between the proper terminology from software engineering and the implantation of Assistance of Systematized Nursing. For such development, it is necessary to recognize some essential concepts.

According to a functionalist view, the systems present themselves as components: the objectives; the entries; the process of transformation of this system; the exits; the controls and evaluations and; the retro-alimentation of the system ${ }^{(2)}$. Despite this fact, the view of nursing systems has advanced toward the idea of complexity, where nursing can be understood as a differentiated and autonomous system, able to continuously regenerate the relationships, interactions, and associations with codes that involve the specificity of nursing care ${ }^{(13)}$. Nursing tries to develop the treatment activities taking into account its own demands, as well as those of the patients and unit managers. Therefore, it is impossible to disregard the whole when trying to promote better practices in nursing. 
INCA nurses, in an empirical format, followed the modeling steps of software to build their assisting system. In software engineering, this process happens in layers or dimensions that are based on an organizational compromise with a focus in quality. The bases for managerial control of projects, where the context enables the implementation of technical methods and respective tools to be used, are founded in this process of construction $^{(3)}$.

It is SNC engineering that permits the implementation of the nursing process in practice. At INCA II, the construction was closer to a model that the SNC dimensions supported, such as software layers. In both SNC and software engineering, the quality is identified as the structure base layer; just above, there is the process layer that, in SNC, is represented by the work developed by the nurses; next is the method layer, which in SNC must be guided by a nursing theory that indicates the tasks, attitudes, and ways of thinking. We highlight that in order for the relationship between method and the theory of nursing to be adopted to guide the practice, consideration needs to be given to the fact that the method and theory concepts are different, corroborating to the current idea that calls attention to the conceptual differences between SNC, the nursing processes, and the methodology of assistance ${ }^{(14)}$. The last layer-the software tools-includes, in the case of SNC, the vocabulary and the classification that can be used to standardize the nursing language.

This model of organization of SNC is constituted in superimposed dimensions mediated by interactive relations. In addition, it is important to mention that the nurses, while implementing SNC, were engaged in the processes needed to acquire Hospital Accreditation, and, consequently, improvement of quality in healthcare. It was thinking with this product and context that they initiated the SNC engineering by creating the GISAE, which allowed them to understand the requirements or quality indicators in healthcare for that unit. The creation fo GISAE happened in a similar format to product engineering, when translating the desire of the client from a series of defined proposals based on the requested engineering. As these requirements are solved, the component engineering enables software, hardware, human, and data engineering models. Despite 
the fact they have different domains, each component's work is integrated based on the established interfaces in the requirements. Afterwards, software engineering takes place, working in modeling, composing, constructing and integrating of the parts as a whole. It can be observed that in software engineering, the focus is reduced as the hierarchy is removed inside of an architecture design. Despite this, this hierarchy will be the reference to the complete construction ${ }^{(3)}$.

As the product engineering steps unfolded to construct the SNC, it was noted that GISAE was the space for making a situational diagnosis through the recognition of fundamental requirements for such construction, which were based on views of the world from each participating nurse. It is worth highlighting that in this moment, the concepts of individual, action, and society, intrinsic to the Symbolic Interactionism ${ }^{(15)}$ were deployed to amplify the recognition of requirements, pointing to the delimitation of elements/ideas that were socially constructed around the symbolic object SNC, according to the interactions and interpretations of the individuals about what they understood as quality healthcare.

Thus, these elements were identified as requirements of SNC and established a situational diagnosis and were later essential in hardware engineering, in the process of aggregating different parts of knowledge to build a system according to the focused requirements. Based on this, forms were developed based on the parallel process of software engineering, and this involved the selection of guidelines or guiding intellectual tools of this system, such as work methods oriented by nursing theories.

Human engineering was considered when nurses developed training acts to operate the system and when they formed an interactive group to both exercise the nursing diagnosis and to share experiences.

The search for updating is necessity for the practice and recognition of the profession, which is always aiming to improve the quality of the services provided ${ }^{(16)}$. In other words, updating works, more than ever, not only in the human engineering processes, but also in the understanding and the architecture of the professional identity of the nurse. Data engineering is related to the strategic actions developed to store information: for 
example, the forms of the pilot project that were identified and registered aiming to help the process of future auditing and consequent retro-alimentation of this system; a thought representing the view about SNC implantation that considers the process as a flow, and therefore the necessity for constant retro-alimentation of any system.

It is important to have an updated comprehension about the system, as the alterations to it happen from time to time. Since the 1970 s, many saw the need to take leave from the reductionist view of many social scientists influenced by the thinking in which atomic units made sense and were reality beyond a system ${ }^{(17)}$. Nowadays, this view is no longer used. In this study, to advance the comprehension of systems and models, it was also considered important that the reflections came from a nursing modeling study to build the electronic medical records of the patient ${ }^{(18)}$.

We emphasize that SNC modeling happened empirically, and was developed based on the experiences of the executive group members, through the acquired knowledge learned through courses and in experience sharing.

\section{CONCLUSION}

In SNC implantation, it was observed that the organization of work processes empirically built were coincident with the steps of software engineering and system architecture. All stages of the requirement survey needed to build the system were followed, except the election of a theoretical reference, as at the time of the interviews, the nurses did not understand what they represented to the overall professional performance. This survey of requirements was the fundamental step to an effective implementation of the system, from the time of its conception to the implementation of practice in a hospital unit by the many social actors involved.

It is through consideration of such questions that we mention the relevance of studies that point out how undergraduates have acknowledged nursing theories and the articulation of those theories in different working scenarios. Therefore, the possibilities of 
detecting gaps that elevate the risk of inconsistency in SNC implementation will be even higher.

\section{REFERENCES}

1. Leopardi MT. Teoria e método em assistência de enfermagem. $2^{a}$ ed. Florianópolis: Soldasof; 2006.

2. Oliveira DPR. Sistemas, organização e métodos: uma abordagem gerencial. $18^{a}$ ed. São Paulo: Atlas; 2009.

3. Pressman RS. Engenharia de software: uma abordagem profissional. 7a ed. São Paulo: MCGRAW-Hill; 2011.

4. Nascimento KC, Backes DS, Koerich MS, Erdmann AL. Systematization of nursing care: viewing care as interactive, complementary and multi-professional. Rev Esc Enferm USP. 2008; 42(4): 643-48.

5. Conselho Federal de Enfermagem [homepage on the internet]. Resolução COFEN358/2009. Dispõe sobre a Sistematização da Assistência de Enfermagem e a implementação do Processo de Enfermagem em ambientes, públicos ou privados, em que ocorre o cuidado profissional de Enfermagem, e dá outras providências. Brasília; 2009. [cited 2009 Out 27]. Available from: http://www.portalcofen.gov.br $\angle 2007 /$ materias.asp?ArticleID $=10$ 113\&sectionID $=34$.

6. Moura EL, Kimura AF, Praca NS. Ser gestante soropositivo para o Vírus da Imunodeficiência Humana: uma leitura à luz do Interacionismo Simbólico. Acta Paul Enferm [serial in the internet]. 2010 [cited 2011 Jan 15]; 23(2):206-11. Available from: http://dx.doi.org/10.1590/S0103-21002010000200009.

7. Strauss A, Corbin J. Grounded theory methodology: an overview. In: Denzin NK, Lincoln YS, editors. Handbook of qualitative research. London: Sage; 1994.

8. Dantas CC, Leite JL, Lima SBS, Stipp MAC. Grounded theory - conceptual and operational aspects: a method possible to be applied in nursing research. Rev Latinoam Enferm [serial on the Internet]. 2009 [cited 2010 Jan 16]; 17(4). Available from: http://www.scielo.br/pdf/rlae/v17n4/pt 21.pdf

9. Ministério da Saúde [BR]- [homepage on the internet]. Conselho Nacional de Saúde. Comitê Nacional de Ética em Pesquisa em Seres Humanos. Resolução No 196 de outubro de 1996: diretrizes e normas regulamentadoras de pesquisa envolvendo seres humanos [Internet]. Brasília: Ministério da Saúde; 1996. [cited 2009 Set 01]. Available from: http://conselho.saude.gov.br/resolucoes/1996/Reso196.doc

10. Fuly PSC, Marins DS. Validation of an application for pediatric nursing: descriptive study. Online braz $\mathrm{j}$ nurs [periodic on the internet]. 2012 Oct [cited 2012 Nov 05]; 11 Suppl 1: 432-9. Available [rom: http://www.objnursing.uff.br/index.php/nursing/article/view/3800

11. Bohm D. O Pensamento como um sistema. São Paulo: Madras; 2007.

12. Bertalanffy L. Teoria geral dos sistemas: fundamentos, desenvolvimento e aplicações. 3a ed. Petrópolis: Vozes; 2008.

13. Backes DS, Backes MS, Erdmann, AL. A Prática Social Sistêmica do Enfermeiro na Perspectiva Luhmanniana. Rev esc enferm USP [periodic on the internet]. 2011 Mar [cited 2012 Nov 19]; 45 (1): 116-21. Available from: http://www.scielo.br/scielo.php?script=sci arttext\&pid=S0080-

62342011000100016\&lng=en.http://dx.doi.org/10.1590/S008062342011000100016 .

14. Fuly PSC, Leite JL, Lima SBS. Concepts associated to systematization of nursing care in Brazilian journals. Rev Bras Enferm. 2008; 61(6): 883-7. 
15. Blumer H. Symbolic interactionism: perspective and method. Englewood Cliffs-NJ: Prentice-Hall; 1969.

16. Espírito Santo FH, Porto IS. Cuidado de enfermagem: saberes e fazeres de enfermeiras novatas e veteranas no cenário hospitalar. $2^{a}$ ed. Rio de Janeiro: UFRJ/EEAN; 2008.

17. Blumer H. George Herbert Mead and human conduct. Califonia: Altamira; 2003.

18. Fuly PSC. Modelagem do processo de enfermagem para o prontuário eletrônico do paciente [dissertação]. Rio de Janeiro: Universidade Federal do Rio de Janeiro Coordenação dos Programas de Pós Graduação em Engenharia; 2004.

\section{Received: 19/11/2012}

Approved: 24/01/2013 